\title{
From the "terrain" to "territory": which contributions from mobility and bus drivers' activity towards local development?
}

\author{
Liliana Cunha ${ }^{\mathrm{a}, \mathrm{b},{ }^{*}}$ and Marianne Lacomblez ${ }^{\mathrm{b}}$ \\ ${ }^{a}$ Universidade Católica Portuguesa, Rua Diogo Botelho 1327, 4169-005 Porto, Portugal \\ ${ }^{b}$ Centro de Psicologia da Universidade do Porto, Universidade do Porto, Rua Alfredo Allen, 4200-135 Porto, \\ Portugal
}

\begin{abstract}
The focus of the present analysis is on the work of drivers in the public road passenger transportation sector in Portugal and on its specific contribution to local development. This approach dissociates itself from the one that places mobility as a "paradigm" of the contemporary societies and considers that the increase in mobility registered in the latter years is, in itself, revealing of development. For field work, a public transportation line, in an urban context, and a network of lines, in a rural context were chosen. In each of these contexts, the drivers' work was analyzed in real situations and semi-structured interviews were held with 16 of them: ten drivers in an urban context and six in a rural context. Considering the point of view of the work activity, enabled us to abandon the dominant perspectives that tend to highlight the social inequality of the mobility conditions (between those who use a private vehicle and those who need to use public transportation), to reflect on the characteristics of the mobility spaces which benefit or limit it, contributing to other inequalities. What is the importance of the space for mobility besides its support? How is it considered in the drivers' work?
\end{abstract}

Keywords: Transportation; Mobility; Drivers; Territory; Inequalities

\section{Introduction}

Mobility constitutes an identity trait for the contemporary societies. "Keep Europe moving": this was how it was announced in one of the Commission's Communication to the Council and the European Parliament [6], the will to make mobility, at European level, accessible to all citizens, recognizing it as an indispensable condition for social and economic integration and cohesion. The abolition of border controls between Member-States, the free circulation of goods, people, services and capital constitute one of the pillars of the European construction - article 3 of the EEC Treaty [18].

If mobility breaks the ties imposed by distance, it is right to question which are the results generated by the effects of people displacements. On the one hand, the effects resulting from the increase of individual mobility are already well known, such as is the case of overcrowding of public space causing traffic jams or the increase of pollution and road accidents. The right to mobility, as an expression of freedom, runs the risk of becoming compromised with the exaltation of individualized models in transportation, which supposedly would guarantee added mobility and flexibility. That is to say, the increase on a large scale of the use of the car ends up by having a counter effect on the intention of being more mobile. On the other hand, the layout of the traffic routes also contributes to increase the population density in those areas, which in articulation with a regular transport system may be generator of new centralities and contribute to the redesign of the territories [15].

This means that the transport systems and their performance have a differentiated impact on mobility: subjacent to the register of an increase in mobility - Eurostat data [8] indicate an increase in the distances covered by the travelers, in the European Un-

${ }^{*}$ Corresponding author. E-mail: lcunha@porto.ucp.pt 
ion, of about $14 \%$, between 1995 and 2003 - is a more evident increasingly use of the car. So, what can be said about the collective public means of transportation?

First of all, it is necessary to establish the difference between transportation and mobility, concepts which are often confused and used indiscriminately. If transportation corresponds to a tool, to a means of access and is synonymous of traveling between "two points", identified as "origin" and "destiny", mobility in Amar's perspective [1] implies the meaning of a feature of the people, the societies or even the territories (p. 41, free translation). Nevertheless, we disagree with this perspective of mobility, considering that it is not a quality per se intrinsic to people or to territories. Our approach to mobility consists of understanding it as a result of options, criteria which define it and give it form, that is, as a result of the intentionality of the actors which conceive it and produce it. In this manner, for us, the passage from transportation to mobility refers to the manifestation of human activity.

\section{The (universal?) right to mobility}

Transportation constitutes a condition for participation in social life, access to schooling, to health, to work and other activities and services, and is, therefore, equally a condition for social integration and citizenship [3]. Moreover, it is because the resources required for social life are not equally distributed in space, neither are the individuals provided with the same opportunities to have access to them, that public action in this area is justified and intervention regarding the availability of effective transportation conditions to ensure social equity.

The recognition of the legitimacy of this right is patent in the notion of public service given to this activity sector, as consecrated in the EEC Treaty (article $\left.73 .^{\circ}\right)$ [18], and in the requirement to fulfill certain public service obligations on the part of the service companies, as foreseen in Regulation (ECC) n. ${ }^{\circ}$ $1191 / 69$, of 26 June [16], related to "the obligation to operate, the obligation to carry and tariff obligations" (article 2. ${ }^{\circ}$, item 2).

The imposition of these obligations is, nowadays, even more relevant, considering that following the 90 s of the 20th Century, other logic became imperative in the sector. The "common transportation policy", registered since the EEC Treaty, was achieved only in this period, as well as the guidelines which it foresees, coherent with an organization based on a market logic and on the free play of competition [19].

The most paradigmatic example of these guidelines corresponds to the experience of the liberalization of the bus service in the United Kingdom, which favored "direct competition on "the road" and free pricing. Quality safeguards are restricted to minimum safety requirements" [7, p.40]. The cost for the users of this initiative was immediately felt, starting by the lack of integration of the different means of transport (articulating the road and railway services), besides the "information to passengers became non-existent because of competition between companies" [7, p.40].

Outside the European context, the existence of non regulated transport markets is observed in various cities of the said "developing" countries: in certain African, Asian, Latin American countries, the majority of the services are provided by private competing companies, organized groups or on an individual basis, and the means frequently used, besides the traditional bus, may be the mini-bus, vans or private vehicles [20]. These transport systems are often of a precarious nature, in spite of the high demand (not very high indicators of ownership of private vehicles), taking into account, namely: the priority given to the reduction of the fare prices in detriment of investment on safety, reliability and comfort, the low capacity to invest in other forms of collective transportation; lack of regulation for road circulation (buslanes, traffic lights priority system for public transportation, ...).

\subsection{Mobility in a national context: what remains invisible in the "general surveys on mobility"?}

The execution of surveys to define the traveling of individuals in a determined territorial context is based, not rarely, on the construction of matrices origin/destiny, which highlight the place of origin and destiny of the journey, normally the one on which the respondent is intercepted [4].

With the "general surveys on mobility", of a national nature, carried out every ten years in a more global scope of the census surveys, the aim is to obtain information which will enable allow to characterize mobility of short duration of the resident population, by means of a set of variables such as the number of journeys made, time of journeys, duration of journeys, means of transportation used, among other factors [4]. 
The critical observation of what was registered on displacements also enabled us to define our position when faced with this "picture" of mobility: "more than the sum of the journeys carried out on public space for a set population, mobility is the dynamic expression of the life of a society on its territory" [5, p.114, free translation]. Moreover, one of the paradoxes of these surveys relates precisely to the time gap of their production: the general surveys on mobility take place every ten years and, in reality, the data on mobility appears to be much less stable than we may think.

These surveys frequently express a functionalist view, of reference to the places of departure and arrival, of the motives for the journeys and their respective duration and of the means of transportation used. However, they never or very rarely deal with the real displacement conditions effectively provided [10], considering the transportation options which people have access to, since the use of a certain means of transportation is not always deliberate, but may be taken for lack of other alternatives.

We, therefore, consider that other approaches have to be pursued in order to show what is also happening in the real work situation of those who transport.

\subsection{An analysis of collective mobility}

With the steady increase in the use of individual transportation, there was a turnaround in the outlook towards collective transportation and its importance as a more "sustainable" means of transportation (less polluting, generating less traffic congestion) became evident. Nevertheless, a project of sustainable mobility can not be defined benefiting only, or especially, an intervention regarding the costs associated with an increase in the number of displacements; on the contrary, the costs of reduced mobility, the limitations at the level of accessibility, the situation of the suburbs, the demographic differences, require that the "residual" statute [17] is abandoned which, at times, is given to these conditions.

The delimitation of the terrain of analysis in this sector could not be indifferent to these territorial disparities. Contrary to emphasis on the movements in the space or on what limits them, we also endeavored to understand what gives "form" to mobility, and territory is one of the determinants of its possible configuration. We assumed that mobility cannot be thought about "desadherence", or at a distance from the territorial specificities, even if the notion of territory is polysemous, simultaneously defining a space which is not neutral or appropriate, a governance delimited space, but at the same time a collective space to provide "common interest" and sharing of values.

Based on what has been discussed, we propose the study of a specific form of mobility by public transportation - collective passenger transportation by road - with emphasis on the intentionality of the actors who take part in this mobility system and in their unique contribution to the change in the dynamics of collective life.

\section{Methodology}

\subsection{Research questions}

The concept that mobility is produced and a producer of places, has made us choose to consider in our study the work of the drivers, integrated in the research not only as "transporters", but also as producers of accessibility and mobility conditions.

We fully subscribe an interpolation shared by [14]: at a time of assertion of the "right to mobility" and declaration of a "generalized mobility" [9], is this not an attempt to conceal the existing inequalities, with false debates? If the objective of mobility is to promote accessibility to individuals located in places that are differentiated, will mobility also be unequally accessible?

\subsection{Sample}

Included in the scientific tradition of the ergonomics of the activity, two case studies are presented in the scope of this research, developed in an urban context and a rural context.

Besides the analyses of the activity carried out in a real work context, semi-structured interviews took place with 16 drivers -10 drivers that work in the bus line under study, in an urban context, and 6 drivers that work in one or more bus lines integrated in the same transport network, in a rural context. It is to be referred that the criteria for the choice of the drivers included the access conditions to those workers and their availability, as well as their work experience on the selected lines. 


\subsection{Procedures for data collection and data treatment}

The methodology of case study is defined by Yin [21], as "an empirical investigation which studies a contemporary phenomenon in its real context, especially when the boundaries between the phenomenon and its context are not clearly evident" (p. 13, free translation).

The two case studies that we present have in common the fact that they were developed with an unavoidable reference to the analysis of the drivers' work activity, in real context. The first case takes as analysis axis a specific bus line which is run by three distinct companies, in an urban context. Our second case study has as common denominator the emphasis on the drivers' work and on its perspective, but in a different context - this study is part of a redesign project of the public transport network of a council area in the Center of Portugal.

In the scope of the analyses of the work activity carried out, in real context, observation was the main technique. The aim was to identify and understand the characteristics and determinants as well as consequences of the activity in each specific context.

With regards to the workers discourse on their work activity, interviews were held on issues related to criteria on the more relevant features of the transportation system, the options of work organization and the strategies developed by the companies and drivers, according to the objectives defined for the provision of this public service. All the interviews were recorded and transcribed, followed by an analysis of the content with the use of Tropes ${ }^{1}$ software. The use of quantification, based on the analysis of the content, took place through a statistical technique which facilitates the organization and interpretation of the data - the "Principal Component Analysis" (PCA) [12].

\section{Results and discussion}

The results showed that, at least two variables (independent variables), characterizing the drivers and their work, were more differentiating in their discourse: these were "the performance context" (urban/rural) and the variable that we identify as "unionization" (drivers trade union members/ drivers not union members).

\footnotetext{
${ }^{1}$ The Tropes version used corresponds to the 7.0 USB version, distributed by CYBERLEX (http://www.cyberlex.pt).
}

From the reading of the graph of figure 1, we may highlight the fact that in relation to the first dimension (abcissa axis), which represents $35,70 \%$ of the total variance, we verify an opposition between the category "territory" and the categories "protagonists" and organization and service provision", although it is the latter variable which polarizes the differences. It is also observed that the ones who most mention "territory" are the participants who work in a rural context and are non union members, while those who most mention "protagonists" and "organization and service provision" are the participants who work in an urban context and are union members.

In an urban context, the references in category "territory" are associated to conflicts in the use of the space (namely, the places and times of highest congestion). The drivers in the rural context, on the other hand, refer more to the difficulties in the use of the space for collective mobility (topographic features of the territory which interfere with the bus circulation) and, which justify the fact that for some people the use of public transport remains inaccessible. This is even more relevant, knowing that the number of daily bus services is very limited, taking into account the low population density which characterizes this region. The analyses of the activity also showed that these drivers often have to make detours to the defined route plan, in an attempt to ensure that the bus routes are closer for some people. 


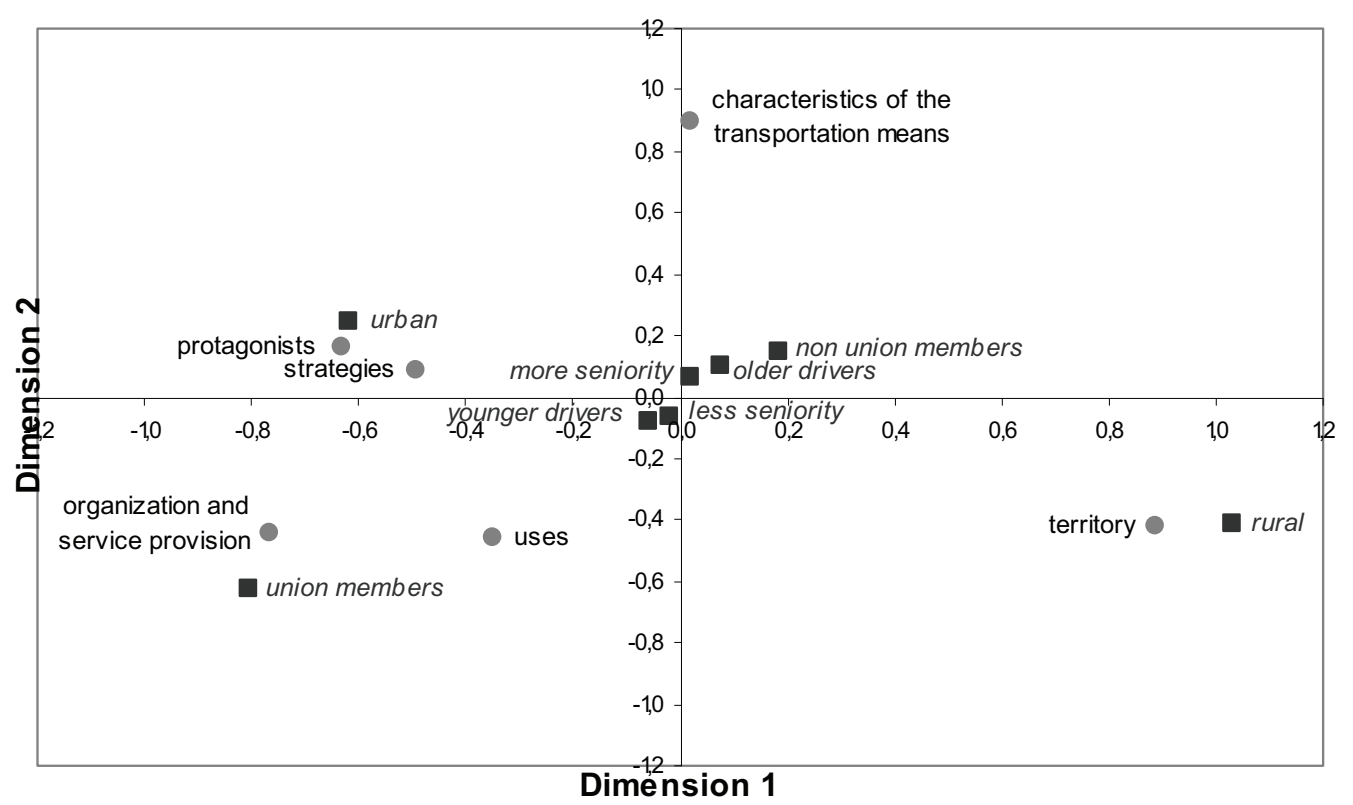

Fig. 1 - Graphic representation of the dimensions found at PCA with positioning of the active variables (discourse categories) and the supplementary variables (age, seniority, union membership, performance context).

Legend: "Active variables" (dependent variables): points filled in grey; "Supplementary variables" (independent variables) squares filled in dark grey and identification written in italics.

These results show the immediate need for two distinct approaches on "territory": for the drivers in an urban context, the notion of territory is associated with an attempt to control the space, a space which is always limited and on which conflicts inherent to its use take place [11]; for the drivers in a rural context, the notion of territory "imposes" itself in the drivers' work activity. On the one hand, the spaces defined for transport are not always facilitators of collective passenger transport, on the other hand, taking into account that this refers to territories where a lower population density is registered, the bus route does not always ensure proximity to the areas of residence or its easy access. These constraints were observed in the studies of the activity in real working context, as well as the attempts of the drivers in order to redesign the "territories of collective mobility".

If we consider the variable "unionization", we observe that the drivers that are not union members are the ones that most talk about territory, referring to it as a restricting factor in their activity; the drivers who are union members, in turn, talk more about "protagonists" and "organization and service provision". The fact that they are union members contributes, in this case, to a point of view more focused on the actors who intervene in the design and implementation who intervene in the design and implementation of the transport services and in the work organization options defined according to the objectives pursued by the companies. If the non union member drivers seem to focus more on their concrete and unique experience, and the union member drivers more on the options that define everyone's work, we may also identify here the argument between a "conscious individual", held by the former, in relation to a "collective consciousness" revealed by the latter's point of view [13].

In relation to the second dimension (ordinate axis), which represents $23,77 \%$ of the total variance, we verify a positive saturation in the category "characteristics of the means of transportation". It is mainly the non union drivers who make statements that we associate with this category of analysis. In effect, it is a category which includes excerpts which correspond to descriptions about what characterizes the bus transport system. It is not necessarily a category crossed by the activity, by what is experienced in the real context. The drivers refer to this category mentioning the type of most frequent users of the service they provide, the times and places of circulation, their work tools, that is, the notion of displacement in 
space-time is more enhanced here than the references to the specific conditions inherent to their work.

\section{Conclusions}

The design of a public transport service frequently has as reference the model of urban mobility, based on a repetitive principle: the same transport, the same itinerary, for everybody and at the same time [2]. The low population density which is a feature of certain areas requires, however, an adjustment of the public transport network to the demand variations, more visible in this type of contexts. In the absence of regular intervention on these public transport networks, it is the drivers' work that comes up as an 'adjustment variable" of the transport system itself to the concrete needs of the users, even though their point of view is not always recognized, nor their specific contribution.

The course of our research did not assume, at first, the territory as a category of analysis. On the contrary, if in effect we assumed a "terrain approach", a terrain which we chose since it allowed us to accompany intervention projects in process, the importance of an analysis of the mobility "embedded" in the territory, ended up by moving our analysis, integrating it in the reflections produced in the scope of this study.

If, on the one hand, the places or rather their characteristics determine the type of possible journeys, on the other hand, these journeys which produce "proximity" also create places and, in this manner, there is the need to recognize the territory not as a form of indexation of the phenomena to be analyzed, but even as an object of research, as a category of analysis allowing other elements to be considered in the apprehension of the reality.

The promotion of local development, in part determined by an intervention on the conditions of mobility, should not neglect the consideration of the work activity contribution, more than assuming that it is an attribute of the territories and the people, which would ultimately end up by reducing the possibility of change. What we intend to sustain is that the initiatives assumed by the drivers in their activity, in a micro level of analysis, cannot be disarticulated from other measures of collective action in the scope of mobility.

\section{References}

[1] G. Amar, Homo mobilis. Le nouvel âge de la mobilité, Éditions Fyp, France, 2010.

[2] F. Ascher, Les nouveaux principes de l'urbanisme, Éditions de l'Aube, La Tour d'Aigues, France, 2010.

[3] A. Bourdin, Les mobilités et le programme de la sociologie, Cahiers Internationales de Sociologie, CXVIII (2005), 5-21.

[4] D. Carvalho and F. Gomes, Inquéritos Gerais à Mobilidade: os casos de Porto e Lisboa. Alguns indicadores de mobilidade, III Congresso Português de Sociologia, Práticas e processos da mudança social, Celta Editora, Lisboa, 1996, pp. 1-11.

[5] C. Cirillo, E. Cornélis, J.-P. Hubert and P. Toint, Les enquêtes sur les comportements de mobilité, et après?, Reflets et Perspectives, XLIII (2004), 111-121.

[6] Communication from the Commission to the Council and the European Parliament, Keep Europe moving - Sustainable mobility for our continent. Mid-term review of the European Commission's 2001 Transport White Paper, Brussels, 2006, $\operatorname{COM}(2006) 314$ final.

[7] European Commission Green Paper, The citizens' network. Fulfilling the potential of public passenger transport in Europe, Brussels, 1995, COM(1995) 601 final.

[8] EUROSTAT, Le transport de voyageurs dans l'Union européenne. Statistiques en bref, Communautés européennes, Luxembourg, 2006.

[9] P. Lannoy and T. Ramadier, dirs., La mobilité généralisée Formes et valeurs de la mobilité quotidienne, Editions Bruylant, Louvain-la-Neuve, Belgium, 2007.

[10] M.-H. Massot and J.-O. Orfeuil, La mobilité au quotidien, entre choix individuel et production sociale, Cahiers Internationaux de Sociologie, CXVIII (2005), 81-100.

[11] P. Melé, Identifier un régime de territorialité réflexive, in Territoires, territorialité, territorialisation: controverses et perspectives, M. Vanier, Presses Universitaires de Rennes, Rennes, 2009, pp. 45-55.

[12] J. Moroco, Análise estatística, com utilização do SPSS, Edições Sílabo, 2003.

[13] I.Oddone, A. Re and G. Briante, Redécouvrir l'expérience ouvrière. Vers une autre psychologie du travail?, Editions sociales, Paris, 1981.

[14] J.-M. Offner, Les territoires de l'action publique locale. Fausses pertinences et jeux d'écarts, Revue française de science politique, 56 (2006), 27-47.

[15] E. Pacheco, Os transportes colectivos rodoviários no Grande Porto, Geografia, Revista da Faculdade de Letras da Universidade do Porto, VIII (1992), 5-64.

[16] Regulation (EEC) n. ${ }^{\circ} 1191 / 69$ of the Council, of 26 June 1969 , on action by Member States concerning the obligations inherent in the concept of a public service in transport by rail, road and inland waterway.

[17] Y. Schwartz, Travail et ergologie, in : Reconnaissances du Travail. Pour une approche ergologique, Y. Schwartz, dir., PUF. Paris, 1997, pp. 1-37.

[18] Treaty establishing the European Economic Community, Rome, 1957.

[19] V. Valentin, Les conceptions néo-libérales du droit, Éditions Economica, Paris, 2002.

[20] V. Vuchic, Urban Transit: Operations, Planning and Economics, Editions John Wiley \& Sons, New Jersey, 2005.

[21] R. Yin, Case study research. Design and methods, Thousands Oaks, Sage, USA, 1994. 